\title{
sciendo
}

\section{Basketball Game-Related Statistics that Discriminate Between European Players Competing in the NBA and in the Euroleague}

\author{
by \\ Rūtenis Paulauskas ${ }^{1}$, Nerijus Masiulis'ㄹ, Alejandro Vaquera ${ }^{3}$,Bruno Figueira ${ }^{4}$, \\ Jaime Sampaio ${ }^{5}$
}

\begin{abstract}
This study aimed to identify the game-related statistics that discriminated between Euroleague basketball players and European basketball players playing in the NBA, when competing in the same event (EuroBasket 2015). There was a total of 78 matches played by 24 teams in two groups of analysis: NBA, participants in the European Championship who played in the NBA season of 2014-2015 $(n=26)$; Euroleague, participants in the European Championship who played in the Euroleague season of 2014-2015 $(n=82)$. The players' performance variables were normalized to the time they spent on the court. To identify which variables best discriminated between the NBA and the Euroleague performance profiles, a descriptive discriminant analysis was conducted. Structure coefficients (SC) from the matrix greater than $|0.30|$ were interpreted as meaningful contributors to discriminating between the groups. The results revealed a significant function ( $p=0.008$, canonical correlation of $0.51, \Lambda=0.74$, reclassification $=84.2 \%$ ) and substantial performance differences in game-related statistics much related to the influence of body size (body height and mass), such as two-point field goals made $(S C=0.42)$ and missed $(S C=0.40)$, free-throws made $(S C=0.55)$, defensive rebounds $(S C=0.62)$, blocks $(S C=0.48)$ and suffered fouls $(S C=0.34)$. No differences were found at the level of game-related statistics indirectly related to perception, such as assists, turnovers or steals. Also, the greater body size in NBA players was likely related to higher variability in performance, thus, being an important topic for coaches and recruiters to analyse.
\end{abstract}

Key words: performance profile, analysis, game-related statistics, discriminant scores.

\section{Introduction}

Sports performance is the expression of complex interactions between physiological fitness, psychological preparedness, physical development, biomechanical proficiency, and tactical awareness, amongst several others (Glazier, 2015). There is no particular predominant theory of sports performance, however, several approaches from environmental determinism (Bale, 2002) to ecological psychology (Gibson, 1986) clearly suggest that human behaviour is to be understood in reference to their specific environment. In fact, at both intra- and inter-individual levels of analysis, the patterns of coordination and control that determine performance outcomes, seem to emerge from the interacting organismic, environmental, and task constraints of coordinative structures (Glazier, 2015). In basketball, several available studies have used game-related statistics to measure player's performance in competitions (Hughes and Bartlett, 2002), allowing to assess offensive and

\footnotetext{
1 - Faculty of Sport and Health, Lithuanian University of Educational Sciences, Vilnius, Lithuania, Faculty of Sport Biomedicine,

Lithuanian Sports University, Kaunas, Lithuania.

2 - Faculty of Sport Biomedicine, Lithuanian Sports University, Kaunas, Lithuania.

3 - Faculty of Sport Science, University of Leon, Leon, Spain.

4 - Faculty of Sport Biomedicine, Lithuanian Sports University, Kaunas, Lithuania; Research Center in Sports Sciences, Health Sciences and Human Development, CIDESD, Vila Real, Portugal.

5 - Research Center in Sports Sciences, Health Sciences and Human Development, CIDESD, Vila Real, Portugal.
} 
defensive actions either in a match or during an entire season (Ziv et al., 2010).

The obtained results allow to adequately assess and describe performance outcomes at all standards of competition. In the National Basketball Association (NBA), which is consensually the most competitive professional basketball league in the world, most research has identified the field-goal percentage and defensive rebounds as the game-related statistics that most contribute to success (Summers, 2013). In most particular scenarios, such as the regular season games, the turnovers might appear as a strong contributor to team success, whereas in playoff games, the importance of defensive performance seems enhanced (Teramoto and Cross, 2010). Accordingly, an analysis focused on contrasting NBA all-star with non-all-star players has revealed that the all-star performed consistently better within 12 feet of the basket, possibly a result of optimized attentional processes, that are essential for perceiving the appropriate environmental information (Sampaio et al., 2015).

In European basketball, some studies have found that performance depends primarily on shooting 2-point field-goals and on securing defensive rebounds (Karipidis et al., 2001; Sampaio and Janeira, 2003). In close contested games, however, fouls and free-throws exhibit increased importance for determining the game outcome compared to lesser contested games (Kozar et al., 1994; Sampaio and Janeira, 2003). In playoff games, recent research found different relative importance of several factors in more competitive stages of the Euroleague season, in particular for shooting percentages, assists and turnovers, defensive rebounds and fouls committed (Utku Ozmen, 2016).

At different times, NBA and Euroleague teams have played a number of friendly matches. Currently, NBA teams have an overall winning record of 73-15. Despite this superiority, the number of European players competing in the NBA is increasing. In the $2014-2015$ season, there were a total of 57 European players coming from 21 countries competing in the NBA. One of the most important topics in high-level competition is related to transitions of players between different leagues in order to optimize player's selection and development to reach higher standards. There have been previous attempts to compare players' performances in different leagues. For example, Sampaio et al. (2006) compared playing positions using performances of players that competed in the NBA, in the Spanish and in the Portuguese professional leagues. In the NBA, differences between positions were greater than in the other leagues and possible explanations were attributed to higher athleticism and rule differences. Other studies identified that dunks seemed more frequent in the NBA and hook shots more frequent in European basketball, which can be also be attributed to better athleticism of NBA players (Erčulj and Štrumbelj, 2015). In fact, athleticism has been consistently identified as the key factor that contributes to USA uncontested superiority in the Olympic Games, particularly by increasing game pace and overall effectiveness (Sampaio et al., 2010).

As shown, most research that contrasts NBA and Euroleague players' performances was carried out during different competitions, also being somehow contaminated by particular characteristics of different teams and circumstances. These comparisons raise several methodological concerns because very different environments have different game activity variables such as rules, court dimensions, schedule fixing, competitiveness or psycho-social environment. An interesting methodological alternative would be to contrast these performance outcomes when the players belong to teams participating in the same competition, such as the European championship (Eurobasket). Thus, this study aimed to identify game-related statistics that discriminated between Euroleague basketball players and European basketball players playing in the NBA, when competing in the EuroBasket 2015. We hypothesized that players competing in the NBA would outperform their Euroleague peers in a particular subset of game-related statistics. The identification of these game-related statistics would probably allow coaches to better understand the actions that support the higher-level outcomes, although these variables do not provide conclusive information about the mechanisms underpinning performance.

\section{Methods}

\section{Sample and Variables}

The sample was gathered from the 2015 
European Men's Basketball Championship, which was attended by 24 teams that played a total of 78 matches. The individual performance statistics were selected for two groups of players: NBA, participants in the European Championship who played in the NBA season of 2014-2015 ( $n=26)$; Euroleague, participants in the European Championship who played in the Euroleague season of 2014-2015 $(n=82)$. Data concerning player's profiles and game performance was taken from the official EuroBasket 2015 web site (http://www.eurobasket2015.org/). The Euroleague sample was constituted by $49 \%$ of guards, $36 \%$ of forwards and $15 \%$ of centers, whereas the NBA sample was composed of $23 \%$ of guards, $46 \%$ of forwards and $31 \%$ of centers. These FIBA official sources are consensually considered reliable (Gómez et al., 2016; Sampaio et al., 2015). The collected variables included players' individual characteristics (age, body height, body mass) and match performance profiles (average time played, two-point field goals made, two-point field goals missed, threepoint field goals made, three-point field goals missed, free-throws made, free-throws missed, offensive rebounds, defensive rebounds, assists, committed and suffered fouls, turnovers, steals and blocks). This investigation was approved by the local Institutional Research Ethics Committee and conformed to the recommendations of the Declaration of Helsinki.

\section{Data Analysis}

The players' performance variables were normalized to the time they spent on the court. Afterwards, the descriptive statistics were calculated for NBA and Euroleague players (mean \pm standard deviation). The differences between groups were expressed in percentage units with 95\% confidence limits. Smallest worthwhile differences were estimated from the standardized units multiplied by 0.2 . Uncertainty in the true differences of the scenarios was assessed using non-clinical magnitude-based inferences (Hopkins et al., 2009). Also, the sub-group comparisons were assessed via standardized mean differences and respective $95 \%$ confidence intervals. Thresholds for effect size statistics were 0.2 , trivial; 0.6 , small; 1.2 , moderate; 2.0, large; and 2.0, very large (Cumming, 2012; Hopkins et al., 2009). To identify which variables best discriminated between NBA and Euroleague performance profiles, a descriptive discriminant analysis was conducted. Structure coefficients from the matrix greater than $|0.30|$ were interpreted as meaningful contributors to discriminating between the groups, other contributors were disregarded (Pedhazur, 1982). Validation of discriminant models was conducted using the leave-one-out method of cross-validation (Norušis and Inc, 2005). Statistical significance was set at 0.05 and calculations were performed using the JMP statistics software package (release 11.0, SAS Institute, Cary, NC, USA) and SPSS software (IBM SPSS Statistics for Windows, Version 22.0. Armonk, NY: IBM Corp.).

\section{Results}

The characteristics of the NBA and Euroleague players are presented in Table 1. There were differences between the groups concerning body height, body mass and time played with higher values for NBA players.

The means and standard deviations from the match performance variables are presented in Table 2. The most important variables for differentiating between performances were identified using a descriptive linear discriminant analysis. The obtained function was statistically significant $(p=0.008)$ with a canonical correlation of $0.51(\Lambda=0.74)$ and total reclassification of $84.2 \%$. The structure matrix from the function reflected a strong emphasis on six variables (identified as from $\mathrm{A}$ to $\mathrm{F}$ in Table 2). In general, NBA players exceled their Euroleague counterparts in two-point field goals made and missed, free-throws made, defensive rebounds, blocks and suffered fouls. The obtained equation to calculate the discriminant scores for each player's performance was as follows:

Discriminant score $=-1.7+4.2^{*} \mathrm{~A}+3.9^{*} \mathrm{~B}+10.9^{*} \mathrm{C}+10.2 \mathrm{D}+32.2^{*} \mathrm{E}-$ $4.9^{*} \mathrm{~F}$

Figure 1 depicts differences between the discriminant scores of both groups as expressed by the latent variable from the obtained multivariate function. The group centroids were located at significantly different spatial locations, NBA (1.05) vs Euroleague (-0.33), showing a better overall game performance of the NBA players (Figure 1).

Using this equation, the Euroleague players' performances were reclassified in the original groups with a very high level of accuracy 
(95.1\%), however, the NBA players were poorly reclassified by the obtained mathematical model (42.3\% of accuracy). A detailed intra-group analysis revealed that incorrectly classified cases exhibited poorer performances, particularly in two-point field goals made, defensive rebounds and suffered fouls (Table 3 ).
Figure 2 depicts differences between the discriminant scores of both correctly and incorrectly classified cases as expressed by the latent variable from the obtained multivariate function. The group centroids were located at significantly different locations, incorrectly (0.44) vs correctly classified (1.86), these later showing a much better overall game performance.

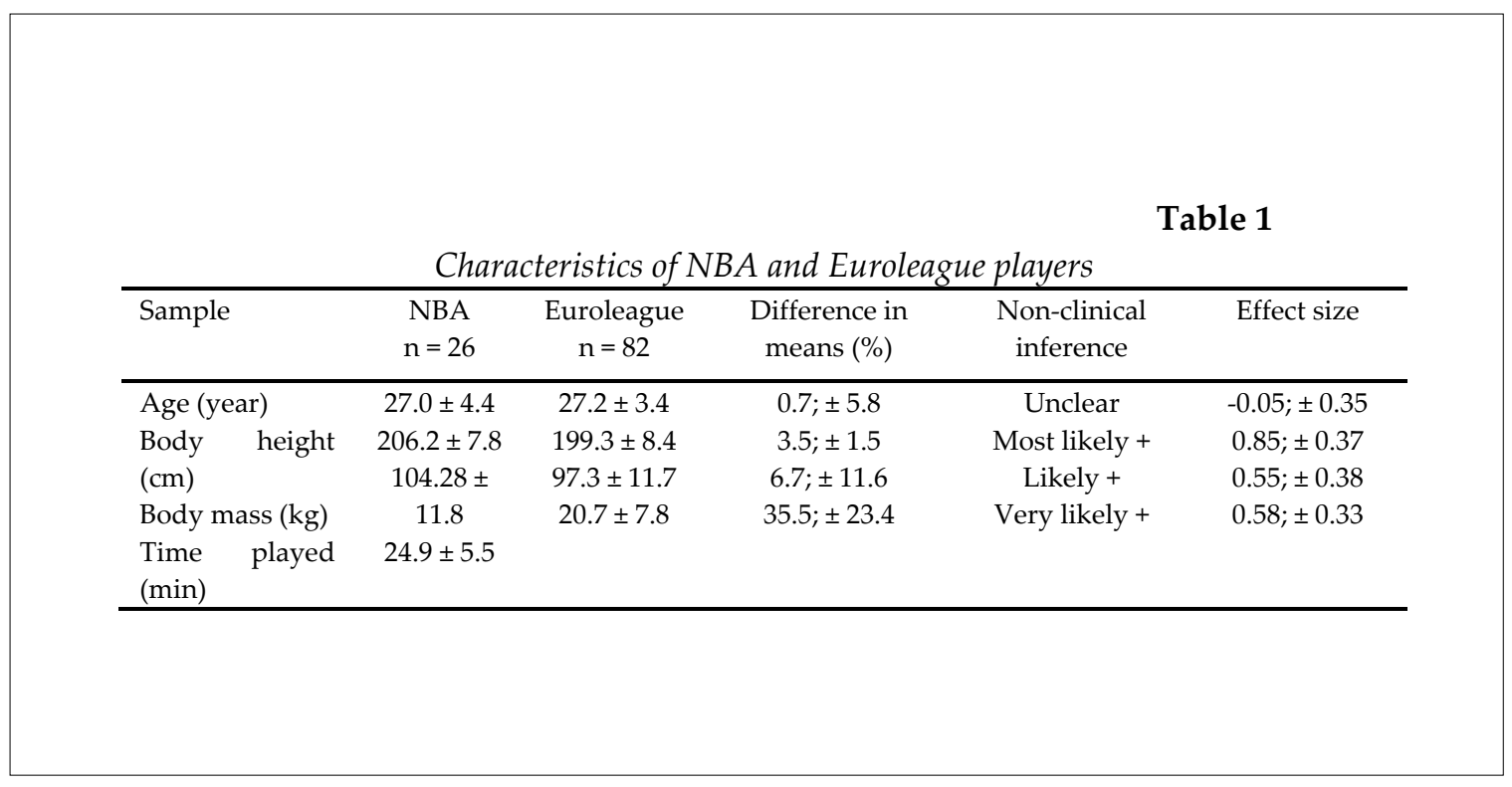

Table 2

Game performance profile of NBA and Euroleague basketball players (per minute of play)

\begin{tabular}{lccc}
\hline Variables & $\begin{array}{c}\text { NBA } \\
\mathrm{n}=26\end{array}$ & $\begin{array}{c}\text { Euroleague } \\
\mathrm{n}=82\end{array}$ & Structure matrix \\
\hline Two-point field goals made (A) & $0.14 \pm 0.06$ & $0.10 \pm 0.06$ & 0.42 \\
Two-point field goals missed (B) & $0.13 \pm 0.05$ & $0.10 \pm 0.05$ & 0.40 \\
Three-point field goals made & $0.03 \pm 0.03$ & $0.03 \pm 0.03$ & - \\
Three-point field goals missed & $0.07 \pm 0.05$ & $0.07 \pm 0.05$ & - \\
Free-throws made (C) & $0.10 \pm 0.06$ & $0.07 \pm 0.04$ & 0.55 \\
Free-throws missed & $0.03 \pm 0.02$ & $0.03 \pm 0.03$ & - \\
Offensive rebounds & $0.05 \pm 0.04$ & $0.04 \pm 0.04$ & - \\
Defensive rebounds (D) & $0.16 \pm 0.05$ & $0.11 \pm 0.05$ & 0.62 \\
Assists & $0.08 \pm 0.05$ & $0.09 \pm 0.06$ & - \\
Turnovers & $0.07 \pm 0.03$ & $0.06 \pm 0.03$ & - \\
Steals & $0.02 \pm 0.02$ & $0.02 \pm 0.02$ & - \\
Blocks (E) & $0.02 \pm 0.02$ & $0.01 \pm 0.02$ & 0.48 \\
Suffered fouls (F) & $0.13 \pm 0.06$ & $0.10 \pm 0.05$ & 0.34 \\
Committed fouls & $0.09 \pm 0.03$ & $0.11 \pm 0.15$ & - \\
\hline
\end{tabular}


Table 3

Game performance profile of NBA players correctly and incorrectly classified by the discriminant analysis (per minute of play)

\begin{tabular}{|c|c|c|c|c|c|}
\hline Variables & $\begin{array}{l}\text { Correctly } \\
\mathrm{n}=11\end{array}$ & $\begin{array}{c}\text { Incorrectly } \\
\mathrm{n}=15\end{array}$ & $\begin{array}{c}\text { Difference } \\
\text { in means (\%) }\end{array}$ & $\begin{array}{l}\text { Non-clinical } \\
\text { inference }\end{array}$ & Effect size \\
\hline Two-point field goals made & $0.17 \pm 0.05$ & $0.11 \pm 0.05$ & $56.5 ; \pm 37.0$ & Very likely + & $1.25 ; \pm 0.65$ \\
\hline Two-point field goals missed & $0.13 \pm 0.05$ & $0.10 \pm 0.05$ & $39.8 ; \pm 44.0$ & Likely + & $0.70 ; \pm 0.64$ \\
\hline Three-point field goals made & $0.03 \pm 0.02$ & $0.04 \pm 0.03$ & $18.1 ; \pm 51.8$ & Unclear & $0.27 ; \pm 0.69$ \\
\hline Three-point field goals missed & $0.07 \pm 0.05$ & $0.07 \pm 0.04$ & $-38.2 ; \pm 45.4$ & Unclear & $-0.54 ; \pm 0.76$ \\
\hline Free-throws made & $0.14 \pm 0.06$ & $0.07 \pm 0.04$ & $111.2 ; \pm 80.7$ & Most likely + & $1.27 ; \pm 0.63$ \\
\hline Free-throws missed & $0.03 \pm 0.02$ & $0.03 \pm 0.03$ & $2.7 ; \pm 53.1$ & Unclear & $0.04 ; \pm 0.69$ \\
\hline Offensive rebounds & $0.06 \pm 0.05$ & $0.04 \pm 0.04$ & $61.0 ; \pm 107.2$ & Likely + & $0.51 ; \pm 0.67$ \\
\hline Defensive rebounds & $0.18 \pm 0.04$ & $0.14 \pm 0.05$ & $40.0 ; \pm 33.7$ & Very likely + & $0.89 ; \pm 0.63$ \\
\hline Assists & $0.07 \pm 0.06$ & $0.08 \pm 0.04$ & $-35.8 ; \pm 39.5$ & Likely - & $-0.53 ; \pm 0.70$ \\
\hline Turnovers & $0.06 \pm 0.03$ & $0.07 \pm 0.03$ & $-9.3 ; \pm 26.8$ & Unclear & $-0.23 ; \pm 0.67$ \\
\hline Steals & $0.01 \pm 0.01$ & $0.02 \pm 0.02$ & $-27.6 ; \pm 37.0$ & Unclear & $-0.48 ; \pm 0.74$ \\
\hline Blocks & $0.03 \pm 0.03$ & $0.01 \pm 0.01$ & $79.5 ; \pm 131.3$ & Likely + & $0.62 ; \pm 0.72$ \\
\hline Suffered fouls & $0.16 \pm 0.06$ & $0.10 \pm 0.05$ & $58.8 ; \pm 46.7$ & Very likely + & $1.05 ; \pm 0.66$ \\
\hline Committed fouls & $0.09 \pm 0.03$ & $0.10 \pm 0.03$ & $-3.0 ; \pm 23.1$ & Unclear & $-0.09 ; \pm 0.66$ \\
\hline
\end{tabular}

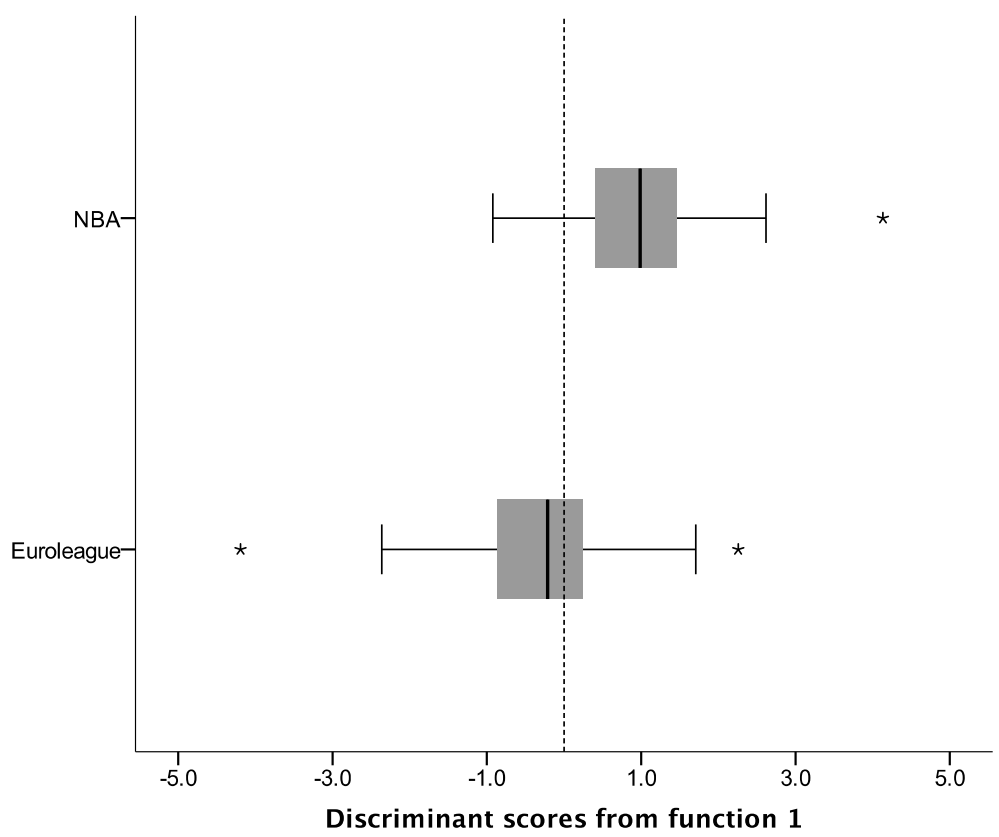

Figure 1

Boxplot from the discriminant scores obtained by players from both groups 


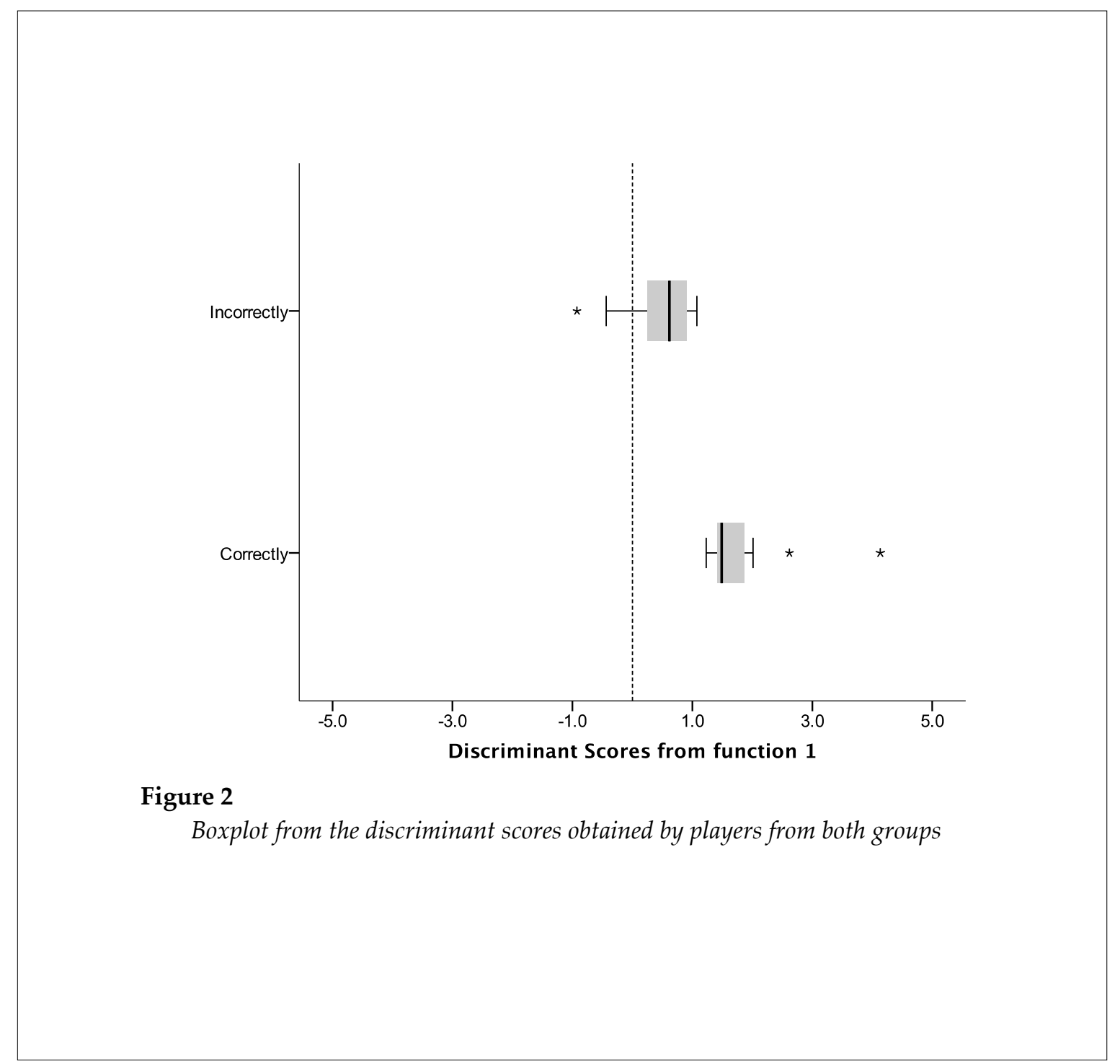

\section{Discussion}

This study aimed to identify gamerelated statistics that discriminated between Euroleague basketball players and European basketball players playing in the NBA, when both competing in the EuroBasket 2015. In general, our results suggest that European NBA players (i) are taller and heavier; (ii) outperform their Euroleague peers in two-point field goals made and missed, free-throws made, defensive rebounds, blocks and suffered fouls; as well as (iii) exhibit poor group homogeneity; a follow up analysis from the incorrectly classified cases allowed to identify poorer performances in twopoint field goals made, defensive rebounds and suffered fouls.

Available research suggests that players' anthropometric indices are key variables to allocate them to specific game positions, in particular by determining how close or far away they are from the basket (Sampaio et al., 2006). The current results show that NBA players still have substantial advantages in body size (body height and mass), thus, it is still a fact that height requirements in the NBA dramatically reduce the population of available players. Interestingly, it is suggested that if the population is restricted, the variability in performance is increased (Berry et al., 2005). In basketball, this effect was already tested by identifying higher variability in performance of taller players (Berry et al., 2005). 
Therefore, it should be no surprise that NBA teams are still particularly interested in recruiting and increasing the population of taller players in their rosters.

From a game standpoint, these players will likely exhibit an ability to play in areas close to the basket, while withstanding physical contact from very strong opponents. Although indirectly, the current results from the discriminant analysis show these somatic effects in contribution from game related statistics to the new latent variable. For example, the fight for rebounds and blocking shots were identified as important performance determinants. In fact, the winning teams are often distinguished by their ability to secure a higher number of defensive rebounds in the game (Gómez et al., 2008; Ibáñez et al., 2008; Trninić et al., 2002) and have an indirect influence on game rhythm by increasing the opportunities for fast breaks (Ibáñez et al., 2009). Accordingly, blocked shots are indicators of individual performance in defence, especially related to the players' height and jumping ability (Balciunas et al., 2006; Ziv and Lidor, 2010). Not surprisingly and confirming the previous statements, NBA players significantly outperformed Euroleague players in these game-related statistics, likely also as a result of their superiority in body size related variables.

The accuracy in shooting field-goals is a relevant factor to achieve success in a game, because these are variables that represent individual and collective offensive effectiveness (Garcia et al., 2013; Malarranha et al., 2013). The current results show a higher number of field goals made and missed by the NBA sub-group, also associated with a greater number of attempts. Therefore, players competing in the NBA have higher participation rates in offense, when compared to their Euroleague counterparts. Research also shows that free-throw variables are determinants of performance, especially in close contested games (Csataljay et al., 2009; Kozar et al., 1994). In the current study, NBA players attempted and made more free throws than Euroleague players, meaning that they seem more active in offensive actions, are able to draw more fouls and create these opportunities to score points from the free-throw line. Finally, the assists and turnovers are not only related with the technical skills of players, but with the perception and action process. In fact, differences between elite athletes and novices in action anticipation are likely accounted for better visual perception in elite athletes, as they actively locate and extract visual information from the environment and integrate them with other sensory inputs (Wu et al., 2015). Other cognitive factors including past experience, motivation and development largely contribute to this process (Wu et al., 2015), however, the current results showed no such differences between NBA and Euroleague players, therefore suggesting similarity in this technical and tactical variables.

The analysis carried out on the misclassified cases was a consequence of poor group homogeneity in NBA players, likely due to higher variability in performance of taller players (Berry et al., 2005). Interestingly, game-related statistics that contributed to this aspect included two-point field goals made, defensive rebounds and suffered fouls.

In summary, the current study captured basketball game performance from NBA and Euroleague players under very similar environmental conditions. The results revealed substantial performance differences in gamerelated statistics significantly related to the influence of body size (body height and mass). No differences were found at the level of gamerelated statistics indirectly related to perception. Additionally, higher body size in NBA players was likely related to greater variability in performance, thus, being an important topic for coaches and scouts to analyse. Coaches and scouts can use these results to optimize the training process by increasing the importance attached to the offensive and defensive processes that allow to increase the actions identified as very discriminant. For example, improving the specific offensive technical and tactical background would allow the players to suffer more fouls and benefit from more free-throw attempts. Most of the bodysize related actions such as rebounding or blocking also include very strong technical and tactical components, such as perceiving and anticipating ball trajectories, and these elements should be emphasized in the training process. 


\section{Acknowledgements}

This research was supported by the Science Fund of the Lithuanian University of Educational Sciences.

Project NanoSTIMA: Macro-to-Nano Human Sensing: Towards Integrated Multimodal Health Monitoring and Analytics, NORTE-01-0145-FEDER-000016, co-financed by Fundo Europeu de Desenvolvimento Regional (FEDER) - NORTE 2020.

\section{References}

Balciunas M, Stonkus S, Abrantes C, Sampaio J. Long term effects of different training modalities on power, speed, skill and anaerobic capacity in young male basketball players. J Sport Sci Med, 2006; 5: 163-170

Bale J. Lassitude and Latitude: Observations on Sport and Environmental Determinism. Int Rev Sociol Sport, 2002; 37: 147-158

Berry DJ, Brook SL, Frick B, Fenn AJ, Vicente-Mayoral R. The Short Supply of Tall People: Competitive Imbalance and the National Basketball Association. J Econ Issues, 2005; 39: 1029-1041

Csataljay G, James N, Hughes M, Dancs H. Performance indicators that distinguish winning and losing teams in basketball. Int J Perf Anal Spor, 2009; 9: 60-66

Cumming G. Understanding the New Statistics: Effect Sizes, Confidence Intervals, and Meta-Analysis. Routledge, Taylor \& Francis Group; 2012

Erčulj F, Štrumbelj E. Basketball Shot Types and Shot Success in Different Levels of Competitive Basketball. PLoS ONE, 2015; 10: journal.pone.0128885

Garcia J, Ibáñez SJ, Martinez De Santos R, Leite N, Sampaio J. Identifying basketball performance indicators in regular season and playoff games. J Hum Kinet, 2013; 36: 161-168

Gibson JJ. The Ecological Approach to Visual Perception. Boston: Houghton Mifflin; 1986

Glazier PS. Towards a Grand Unified Theory of sports performance. Hum Mov Sci, 2015; http://dx.doi.org/10.1016/j.humov.2015.08.001

Gómez MA, Gasperi L, Lupo C. Performance analysis of game dynamics during the 4th game quarter of NBA close games. Int J Perf Anal Spor, 2016; 16, 249-263

Gómez MA, Lorenzo A, Sampaio J, Ibanez SJ, Ortega E. Game - related statistics that discriminated winning and losing teams from the Spanish men's professional basketball teams. Coll Antropol, 2008; 32: 315-319

Hopkins WG, Marshall SW, Batterham AM, Hanin J. Progressive Statistics for Studies in Sports Medicine and Exercise Science. Med Sci Sports Exerc, 2009; 41: 3-12

Hughes MD, Barlett RM. The use of performance indicators in performance analysis. J Sports Sci Med, 2002; 20: 739-754

Ibáñez SJ, Garcia J, Feu S, Lorenzo A, Sampaio J. Effect of consecutive basketball games on the game - related statistics that discriminate winner and losing teams. J Sports Sci Med, 2009; 8: 458-462

Ibáñez SJ, Sampaio J, Feu S, Lorenzo A, Gomez MA, Ortega E. Basketball game-related statistics that discriminate between teams' season-long success. Eur J Sport Sci, 2008; 8: 1-4

Karipidis A, Fotinakis P, Taxildaris K, Fatouros J. Factors characterizing a successful performance in basketball. J Hum Movement Stud, 2001; 41: 385-397

Kozar B, Vaughn RE, Whitfield KE, Lord RH, Dye B. Importance of Free-Throws at Various Stages of Basketball Games. Percept Motor Skill, 1994; 78: 243-248

Lyons M, Al Nakeeb Y, Nevill A. The impact of moderate and high intensity total body fatigue on passing accuracy in expert and novice basketball players. J Sports Sci Med, 2006; 5: 215-222

Malarranha J, Figueira B, Leite N, Sampaio J. Dynamic Modelling of Performance in Basketball. Int J Perf Anal Spor, 2013; 13: 377-386

Norušis MJ. SPSS 13.0 Guide to Data Analysis: Prentice Hall; 2005 
Pedhazur, E. Multiple Regression in Behavioral Research. New York; 1982

Sampaio J, Janeira M. Statistical analyses of basketball team performance: understanding teams' wins and losses according to a different index of ball possessions. Int J Perf Anal Spor, 2003; 3: 40-49

Sampaio J, Janeira M, Ibanez S. Lorenzo A. Discriminant analysis of game-related statistics between basketball guards, forwards and centres in three professional leagues. Eur J Sport Sci, 2006; 6: 173-178

Sampaio J, McGarry T, Calleja-González J, Jiménez Sáiz S, Schelling i del Alcázar X, Balciunas M. Exploring Game Performance in the National Basketball Association Using Player Tracking Data. PLoS ONE, 2015; 10, doi: 10.1371/journal.pone.0132894

Sampaio J, Lago C, Drinkwater E. Explanations for the United States of America's dominance in basketball in the Beijing Olympic Games (2008). J Sports Sci, 2010; 2: 147-152

Summers M. How to Win in the NBA Playoffs: A Statistical Analysis. American Journal of Management, 2013; 13: $11-24$

Teramoto M, Cross CL. Relative importance of performance factors in winning NBA games in regular season versus playoffs. Journal of Quantitative Analysis in Sports, 2010; 6: 11-24

Trninić S, Dizdar D, Luksić E. Differences between winning and defeated top quality basketball teams in final tournaments of European club championship. Coll Antropol, 2002; 26: 521-531

Utku Özmen M. Marginal contribution of game statistics to probability of winning at different levels of competition in basketball: Evidence from the Euroleague. International Journal of Sports Science and Coaching, 2016; 11: 98-107

Wu Y, Zeng Y, Zhang L, Wang S, Wang D, Tan X, Zhu X, Zhang J, Zhang J. The role of visual perception in action anticipation in basketball athletes, Neuroscience, 2013; 237: 29-41

Ziv G, Lidor R. Vertical jump in female and male basketball players - a review of observational and experimental studies. J Sport Sci Med, 2010; 13: 332-339

Ziv G, Lidor R, Arnon M. Predicting team rankings in basketball: The questionable use of on-court performance statistics. Int J Perf Anal Spor, 2010; 10: 103-114

\section{Corresponding author:}

\section{Rūtenis Paulauskas}

Faculty of Sport and Health, Lithuanian University of Educational Sciences,

Studentu g. 39, LT-08106 Vilnius,

Phone: +37069839079

Fax: +37052734858

Email: rutenis.paulauskas@leu.lt 